This is a pre-print version of the essay published in Dialogue and Universalism, 2015/4

\title{
Wolfgang Köhler on facts and values
}

\author{
Riccardo Martinelli
}

1. A talented experimentalist and theoretician, trained in physics no less than in psychology, Wolfgang Köhler famously provided outstanding advancements in the development of the theory of Gestalt ${ }^{1}$. In some of his works, Köhler interestingly developed philosophical ideas as well. To be sure, he never considered himself a professional philosopher. Rather, as a consequence of his permanent commitment to scientific investigation and scientific methods, Köhler was eager to reflect upon the consequences of applying a scientific world view to human life. In his own words, he discussed the question of The place of value in a world of facts, as the title of his 1938 book reads.

In this essay I investigate some of Köhler's philosophical ideas. Köhler competently discusses the problem of facts and values, which is still urgent nowadays. To this purpose, he expresses his views concerning the nature of phenomenological data, the way mental and brain processes are related and the structure of physical reality. Although his philosophical reflexions mainly ensue from his epistemological turn, consisting in the adoption of the Gestalt's point of view in psychology, in The Place of Value in a World of Facts and in other works Köhler goes far beyond Gestalt psychology and develops a consistent and partly autonomous epistemology. In his view, true science cannot allow for the contradiction arising between the complete absence of value-related entities in the physical world and the obvious valuerelatedness of many, or most, human behaviors. Positivism and behaviorism tried to

For a bibliography of Köhler's writings, see Newman 1971. As to his development, see Asch 1968; Ash 1995. 
overcome this gap, arguing for the actual absence of values within both the scientific and human world: human beings, as outcomes of evolution, can be wholly explained as the mere result of ordinary physical laws. Yet, positivists manifestly contradict themselves insofar as they consider factual science as their supreme value. As a reaction to this point of view, Köhler notes, spiritualism argue for the existence of a spiritual principle, and vitalism claims that the laws governing the world of living beings cannot ever be reduced to those of inorganic nature.

Köhler is unsatisfied with all of these views. His arguments have nothing to do with a plea for the intrinsic value of humanity according to spiritualistic, vitalistic (or extra-scientific, e.g. religious) stances. Rather, Köhler insists on the logical inconsistency of spiritualistic attempts and seeks for a different solution within the framework of what he calls "epistemological dualism". As we shall see, Köhler aims at a new interpretation of physical facts and laws that should include (or, at least, should not clash with) the principle of "requiredness" as a basis for a value theory. Köhler is consciously far from developing a wholly detailed theory of value. Nevertheless, the strategy underlying his arguments is quite clear and offers an interesting contribution, enabling epistemology to bridge the increasing gap between natural and human sciences.

My analysis of this theme is organized as follows: in the first place, I present Köhler's intellectual path towards the definition of his philosophical ideas and draw special attention to his concept of "physical Gestalt" (2). Secondly, I illustrate his philosophy of science and his thought in the field of phenomenology, compared to Carl Stumpf's ideas on those matters (3). Finally, I discuss Köhler's solution to the problem of value within the general framework of his "epistemological dualism"(4).

2. Born in Estonia in 1887 from German parents, Köhler soon moved to Germany. He studied in Tübingen, Bonn and Berlin, where he received his Ph.D. under Carl Stumpf's direction in 1909, with a thesis concerning psychological acoustics2. Köhler then moved to Frankfurt, where he cooperated with Wertheimer and Koffka to

2

Köhler 1909. Köhler published four more articles on this topic. 
the seminal experiences that laid the foundations of the Gestalt theory. In 1913, following Stumpf's suggestion, Köhler went to Tenerife, where he directed the anthropoid research station of the Prussian Academy of Sciences. Due to the war, Köhler was forced to stay there longer than he had expected or wanted to. His experimental results concerning intelligent behavior in apes were published in Intelligenzprüfungen an Antrhopoiden, an essay that started a new way of considering animal intelligence ${ }^{3}$. During his years in Tenerife, Köhler also began his researches in physics and conceived a project, whose results were published in 1920 in the volume Die physischen Gestalten in Ruhe und im stationären Zustand. In the early Twenties Köhler assumed the direction of the Institut für Psychologie and succeeded Stumpf in the position of professor of philosophy and psychology in Berlin ${ }^{4}$. Köhler successfully brought about the Gestaltists' point of view both from a theoretical and from an experimental point of view. In 1935, Köhler was invited to Harvard to deliver the William James lectures, later published as The place of value in a world of facts 5 . Back to Germany, Köhler publicly pronounced himself against the persecution of Jews by the Nazis: that would be the last public protest in the Third Reich6. Thanks to his international fame, Köhler was not arrested, yet he had to leave his post and move to the United States. He joined the Swarthmore College and later the Dartmouth College in New Hampshire, where he died in 1967.

An interesting chapter in Köhler's career is represented by his relationship with Stumpf. Stumpf, who had studied under Franz Brentano and had later deeply modified his teacher's views, had devoted himself both to philosophy and to experimental research, contributing to overcome associationism and positivism in psychology and developing some historical antecedent (e.g. "tonal fusion") of the concept of Gestalt. Moreover, Stumpf recommended a sound scientific training to all those who were interested in philosophical issues, and advocated cooperation between natural

Köhler 1917.

Ash 1995, 170; 207.

$5 \quad$ On the circumstances surrounding this invitation see Sokal 1984, $1251 \mathrm{ff}$.

$6 \quad$ See Henle 1978. 
sciences and philosophy? ${ }^{7}$. As we shall see, Köhler shared Stumpf's attitude towards science. In the following paragraphs I also underline some similarities between Stumpf's and Köhler's phenomenological description of the basic facts of consciousness. Still, the remarkable differences between Stumpf's and Köhler's views are to be considered as well. Stumpf never adhered to the Gestalt theory, which seemed simply untenable to him ${ }^{8}$. In turn, in 1913 Köhler sharply criticized a crucial issue of Stumpf's psychological theory, namely, the so-called "unnoticed sensations" and the related hypothesis of constancy between stimulus and sensation9. But then, Stumpf was a relatively liberal teacher, who never aimed at establishing a "school" and sincerely appreciated his students' originality ${ }^{10}$. Despite Köhler's criticism - and, on the other side, his own skepticism towards the Gestalt theory - Stumpf held Köhler in high esteem and actively supported his academic career.

In the above mentioned book, Die physischen Gestalten in Ruhe und im stationären Zustand, Köhler aims at revealing organized, Gestalt-like structures within the physical universe. Hans Driesch and other advocates of vitalism had already allowed for Gestalt-like processes within organic nature11. But Köhler believes that the concept of Gestalt, originally born from the new psychology, can gain full scientific citizenship also in physics. In his attempt, Köhler mainly relies upon James Clerk Maxwell's field theory. Indeed, forces or electric charges within an electromagnetic field show properties that exceed the mere sum of the involved items. As Köhler puts it, they tend to assume time-independent states, with a minimum energy dissipation and maximum entropy. The opponents of Gestalt psychology, who assume that any complex phenomena result from elementary elements and association processes, are thus mistaken when they claim they comply to the methods of physics. Against them,

$7 \quad$ Stumpf 1907. See Fisette and Martinelli, 2015.

$8 \quad$ Stumpf 1939-40, I, 243.

$9 \quad$ Köhler 1913.

10 Stumpf 1924, 441.

11 Köhler 1920, xiv. In his reply to Köhler, Driesch points out that true Gestalts emerge only within the organic world. Köhler's alleged physical Gestalts ensue from an activity performed by the experimenter. Driesch 1925, 5-6. 
Köhler claims that, for instance, the distribution of electric charges in a certain physical body is a "physical Gestalt".

Still, he does not think of the whole physical world as made up of Gestalts. Some facts are obviously the result of a mere combination of forces or processes. Köhler draws particular attention to a special field of the physical world, i.e. the central nervous system. Provided that Gestalts exist within the physical world, then nothing prevents us from believing that the central nervous system also assumes Gestalt-like states ${ }^{12}$. Even more so, since what happens in the brain essentially consists of electric processes. According to Köhler, neural processes and states should not be considered aggregates of isolated units, acting separately and independently of each other. Rather, the central nervous system typically assumes Gestalt-like states ${ }^{13}$. To support this view, since 1920 Köhler introduces a complex interpretation of neural processes in terms of Walther Nernst's theory of galvanic chains. Studying the retinal processes, Georg Elias Müller had already proposed a psychophysical interpretation of Nernst's chains; yet Köhler expands this construct to the whole central nervous system. Accordingly, he hypothesizes that the physiological process underlying a certain spatial perception is a physical Gestalt, whose spatial properties roughly correspond to the perceived Gestalt 14 .

In 1920, Köhler lays the theoretical groundwork for his famous postulate of (psycho-physical) isomorphism. As Köhler would later formulate, "psychological facts and the brain events that underlie them are similar in all their structural characteristics"15. Isomorphism has been often criticized by psychologists and physiologists for its lack of empirical evidence. Köhler always replied to his critics that isomorphism was a working hypothesis, allowing us to explain a certain set of facts concerning perception. Be that as it may, these theses also brought about a debate as

\footnotetext{
12 Köhler 1920, xv.

$13 \quad$ Köhler 1920, 68.

14 Köhler 1920, 189. In any case, Köhler sharply polemicizes G.E. Müller as to the basic concepts of the Gestalt theory: see e.g. Müller 1923; Müller 1926; Köhler 1925a; Köhler 1926. 
to his general philosophical views ${ }^{16}$. Since the perceived Gestalts correspond to the physical world, Köhler seems to adhere to realism. Yet some scholars consider him an idealist, because he claims for no more than a correspondence between neurophysiological states and phenomenal percepts, not material things. I shall discuss this question in the final chapter of this essay. In my view, Köhler's "epistemological dualism" implies neither realism nor idealism: rather, it supports a monistic world view, being an attempt to adhere to facts both in psychology and in physics, matching the immediacy of phenomenology with a robust scientific world view.

3. We can now turn to Köhler's discussion of the problem of value, as illustrated in The place of value in a world of facts. The purpose of the book, stated in the Preface, is "philosophical". In recent times, Köhler notes, doubts have been raised as to whether science is able to contribute to the "fundamental issues of mankind". Is it acceptable that science and philosophy proceed separately? Köhler suggests that they should rather follow a common path. More explicitly, philosophy should learn from science and proceed step by step instead of proposing ready-made solutions for the ultimate questions. Philosophers should learn "patience", that is, a true scientific attitude consisting in the awareness of the limits to one's achievements. Philosophers no less than scientists always leave unsolved problems to other researchers. Köhler was probably influenced by Stumpf, whose ideas concerning the philosophers' compliance with the methods of science are quite the same ${ }^{17}$.

In the first, introductory chapter ("The case against science") Köhler stages a dialogue between a skeptical editor of a magazine's special issue about the Krise der Wissenschaft ("crisis of science") and himself. Unsurprisingly, in the dialogue Köhler

16 For the realistic interpretation see Ash 1995, $177 \mathrm{ff}$. esp. 186. By contrast, Keiler 1980 champions the "idealist" party. For a discussion and in favor of a monistic solution, see Toccafondi 2000, 85-97.

17 Stumpf 1939-40, I, 123: "Philosophy should get rid of the habit of appearing on the scene while claiming the need for a complete and self-contained system that can answer all questions. Its scientific character, rather, is proved just from the fact that philosophy always leaves open many more questions than those it provides answers for". 
plays the role of the champion of science ${ }^{18}$. Nevertheless, the opponent's arguments are consistent. Sciences altogether (the German term Wissenschaft refers to human learning in general) seem indeed unable to contribute to human purposes. Scientists, when they are questioned about the fundamental issues of mankind, usually shy away and prefer to concentrate upon the details of their narrow-minded research. According to the triumphant positivistic stances, science has nothing to do with human values and is avowedly unable to explain them. A human being - positivists say - is nothing but the result of evolution, nothing but $70 \%$ water and $30 \%$ cheap rough chemical elements, and so on ${ }^{19}$. In this reductionistic way, however, positivists lose sight of their objectives. Structural properties, Köhler suggests, supervene the constitutive elements and require a more accurate explanation than the mantra-like recurring refrain nothingbut-something.

As any other individual who firmly believes in science, Köhler aims at defending it against the above mentioned charges. The main question to be faced is the following: are there only "mere facts or, besides mere facts, right and wrong"? Köhler explains:

Let us for the moment give the name value to this common trait of intrinsic requiredness or wrongness, and let us call insight all awareness of such intellectual, moral or aesthetic value. We can then say that value and corresponding insight constitute the very essence of human mental life. Take any major human problem, and you will find that it contains this factor20.

In the course of his analysis, Köhler privileges the rather technical term "requiredness" over "value". As far as the readability of his book is concerned, this choice is questionable; however, Köhler correctly remarks that "requiredness" applies both to logical necessity and to values in the narrower, i.e. ethical and aesthetic

\footnotetext{
18 The Berlin Gestaltists' compliance to scientific methods, and their adherence to science as an ideal form of knowledge, should be stressed against any misinterpretation of the "Gestalt movement" in terms of a kind of holistic mysticism. Together with Lewin, Köhler had cooperated with Hans Reichenbach and planned to start a journal for exact science. See Ash 1995, 261; Milkov, 2011, x, xiv, Milkov 2013, 9-10. The Gestaltists' relationship to the Vienna Circle should also be adequately appreciated. See Kluck 2008 , 48 and passim.
}

$19 \quad$ Köhler 1938, 17.

$20 \quad$ Köhler 1938, 31. 
sense $^{21}$. The main question then becomes: what is the origin of requiredness, as opposed to mere factuality?

Traditional philosophical solutions are inadequate. Plato famously situated values beyond any experience; Kant agreed with him about the transcendence of values, yet included it in the a priori mechanisms of the human mind. Thereafter, pace Kant, naturalism and reductionism took the lead and denied any special meaning to human values. As a reaction, Köhler notes, vitalists attempted to defend organic nature from such naturalistic pretensions, while "Humanists and some philosophers of culture" retreated "still farther back into the realm of the mind and its achievements"22. In this context, Edmund Husserl's great merit was to understand that even logic was in danger, since positivists argued that also logical laws were nothing but laws of "real thinking", and truth (or logical necessity) nothing but a matter of psychological mechanisms. Köhler clearly sympathizes for Husserl's phenomenological method. But he complains that Husserl eventually escaped into the realm of pure logical essence, and - no less than Plato and Kant - left the general question of requiredness unanswered23.

Köhler takes into account recent theories of value, as well. He especially dwells upon the General Theory of Value by Ralph Barton Perry, who defends a subjective theory, according to which values ensue from human interest ${ }^{24}$. Accordingly, as soon as something becomes the object of someone's interest, that thing acquires value. By contrast, Köhler insists on an objective theory of value. Things do not gain value because someone is interested in them - rather, human beings get interested in certain things because they are valuable. But how to defend this point of view, if the world is made up of mere facts?

\footnotetext{
$21 \quad$ Köhler 1938, 37. See De Monticelli 2013.

22 Köhler 1938, 45.

23 Köhler 1938, 53.

$24 \quad$ Parry 1926. See Köhler 1938, 62. Ralph Barton Perry, a student of William James and the author of a renown Jamesian critical biography, was a friendly correspondent of Köhler's, who invited him to Harvard. The Place of Value in a World of Facts is dedicated to him, and Köhler discusses his doctrines at length (see above).
} 
As a first step, in the subsequent Chapter (“An Analysis of Requiredness") Köhler goes back to phenomenology. Yet he deeply modifies Husserl's understanding of it25. In fact, in Köhler's view, phenomenology should not be confined to logic and timeless entities. Phenomenology entails the description of any immediate experience as such, regardless of otherwise acquired knowledge concerning the origin (or the organic basis) of the involved percepts. This task, Köhler admits, is always at risk of misunderstanding, because of a typical ambivalence of some of the crucial terms of phenomenology, that have also an objective meaning. In Köhler's words:

Phenomenally, the bodily 'self' is not a physical entity outside immediate experience as is the physical organism; it is, rather, a percept of which we are aware, enriched by changing moods, attitudes, efforts and activities. Similarly, 'objects' in this discipline are phenomenal things, for instance percepts. (Images, concepts, and the like, are also called 'objects' and not without justification.) Percepts are, of course, not ghosts belonging somehow to the phenomenal 'self.' Those, at least, which we call 'things' look, in general, most 'real', 'independent', 'permanent' and 'substantial'; they often feel 'heavy' and as a rule 'resistant'. All this implies in no sense a contradiction of their nature as phenomenal things. Their place is not in the 'self' - why should these percepts be localized inside another particular percept?-, but in other parts of phenomenal 'space', near or far as the case may be. In this world which is that of naive everyday life, certain parts, events and properties belong phenomenally to the 'self' others belong to 'objects' or, more generally speaking, to the phenomenal environment of the 'self'. The former have the character of 'subjectivity' which, in this sense, is only another name for the fact that they appear and are counted as parts or states of the 'self'; the latter have, in most cases, the character of 'objectivity'. ${ }^{26}$

Köhler clearly distinguishes two aspects within phenomenal experience: subjectivity and objectivity. Phenomenal data have a subjective aspect (the 'self') and an objective aspect ('things'). Probably, Köhler goes on, the subdivision in a subjective and an objective area within human consciousness is progressively acquired, or learned in the course of individual development. At the same time, and without any contradiction, both subjective and objective phenomenal data are "genetically subjective", that is, they belong to the experience of a certain human subject and, as such, depend on the individual's central nervous system. Thus, Köhler makes a point of

$25 \quad$ Köhler 1938, 68. Köhler rejects the tendency of some other phenomenologists towards mysticism and obscure philosophizing (possibly an allusion to Martin Heidegger). 
carefully avoiding any confusion between the phenomenal 'self' and the organic body. The former is part of experience, the latter never appears within it.

Before discussing this theory in the next chapter, let us make a historical digression concerning, once more, Stumpf's influence. For Stumpf as well, there is no "pure" phenomenological investigation. Rather, phenomenology should focus on "regional" research concerning ordinary experience, and especially perceptual issues 27. In a 1906 essay, Stumpf distinguished between appearances (Erscheinungen) and psychic functions (psychische Funktionen). "Appearances" are the basic sense-data (both actually sensed or remembered), and the relations among them; "psychic functions" are all mental activities and states: e.g. perceiving, judging, feeling emotions, desiring, etc ${ }^{28}$. Thus, in Stumpf's view, phenomenal experience has an ultimately dualistic aspect, that cannot be overcome in any way29. As we shall see, Köhler adopts a dualist epistemology too. Furthermore, Stumpf anticipates another of Köhler's tenets when he claims that recognizing objective presentations as the effect of external objects has to do with "the distinction of the body from its environment", slowly developing within conscience during one's growth 30 . Objective and subjective data are thus embedded in basic phenomenology; their distinction is the result of individual evolution. Nevertheless, despite these similarities, one should bear in mind that Stumpf reserved the word 'phenomenology' for a more limited task than Köhler did. For Stumpf, phenomenology is a preliminary science devoted to the analysis of objective sense-data. By contrast, Köhler integrates the analysis of subjective sense-data (i.e. what Stumpf would rather call "eidology") into phenomenology.

4. Relying upon his phenomenological analysis, Köhler faces the main question concerning facts and values in an innovative way. Values, he claims, are objective. This means that there is a certain "vector", whose origin lies in a certain object, in the phenomenal field. This terminology, typical for instance of many of Kurt Lewin's works,

27 Stumpf 1939-40. See Fisette 2015.

Stumpf 1906, 105-106.

Stumpf 1906, 115.

30

Stumpf 1918, 81. 
clearly resembles the field theory in physics. In fact, vectors represent forces defined in a certain field, which is, in this case, the phenomenal field. To explain that, Köhler first reminds his reader of the general postulates of the Gestalt theory:

In Gestalt psychology we distinguish three major traits which are conspicuous in all cases of specific organization or gestalt. Phenomenally the world is neither an indifferent mosaic nor an indifferent continuum. It exhibits definite segregated units or contexts in all degrees of complexity, articulation and clearness. Secondly such units show properties belonging to them as contexts or systems. Again the parts of such units or contexts exhibit dependent properties in the sense that, given the place of a part in the context, its dependent properties are determined by this position 31 .

In order to exemplify the situation, Köhler goes on, let us suppose that a melody in a certain key, e.g. of a-minor, is played on a piano. The resulting chord of this melody, in most cases, will be an a-minor chord. In this case, the a-minor chord is perceived as the "right" chord, while any other chord would break in as a "wrong" one. The requiredness of the a-minor chord, Köhler concludes, is completely objective. It does not depend on a subjective preference. Obviously enough, the melody and the chord are made up of single tones. But the "tertiary quality" represented by its key of aminor dissolves if those tones are presented separately32. Therefore, Köhler notes:

[w]e can analyze the melody, but not in independent parts. That would be destruction of the melody. Its minor-character for instance would be lost. We can analyze the situation of subjective requiredness, but [...] not in independent parts, all taken by themselves. The vector - and requiredness - cannot exist alone any more than a fish can live out of water ${ }^{33}$.

In some cases, the vector originates from another human subject. For instance, the police officer who makes me stop at the crossing, a beggar who holds out his hand towards me. This fact, Köhler believes, does not make any significant exception to the objective explanation of requiredness. Rather, one should distinguish two cases: "in the

\section{$31 \quad$ Köhler 1938, 84-85.}

32 Tertiary qualities correspond to the power of sorting selected effects upon other things or persons. They are even more response-dependent than secondary ones. For instance, the color of a rose is a secondary quality, but its beauty is a tertiary quality. Similarly, in Köhler's example, the sounds are secondary qualities, whereas the a-minor key is a tertiary one. 
first, the vector points toward the object, in the other the object is the point of origin of the vector" 34 .

So far, requiredness has been explained from a phenomenological point of view. Yet, Köhler is far from reaching his final goal. Phenomenology is "the field in which all concepts" - including requiredness - "find their final justification". But then those concepts can and must be applied to extra-phenomenal fields, too35. Consequently, Köhler needs to extend the analysis of requiredness "beyond phenomenology", as the title of the next chapter reads. For the sake of the present concern, I shall distinguish three main steps within Köhler's way beyond phenomenology: (1) the experience of transcendence, (2) the pseudoproblem of realism, and (3) the postulate of isomorphism.

(1) Firstly, Köhler reflects upon the possibility of experiencing transcendence. With this, he does not think of a mystic or religious experience of "transcendent" divine entities. Rather, he draws attention to some liminal case, in which conscious experience seems to require, or imply, an extra-phenomenal world which transcends consciousness itself. In this fascinating analysis, Köhler always takes for granted that there is something beyond phenomenology: a physiological support for consciousness, consisting in the central nervous system. This system never manifests itself phenomenally. We know about it only indirectly, that is, via a series of scientific inferences concerning the biological basis of life and consciousness. Nevertheless, Köhler argues, some experiences let us guess its presence. Since experience does not consist of atomic facts, but rather of oriented vectors, nothing prevents us from thinking of a vector pointing from inside experience outwards, or vice versa. As an example, Köhler refers to memory. 36 It is commonly experienced that sometimes we repeatedly fail to recall a certain name although, at the same time, we feel close to remembering it. In Köhler's words:

\section{$34 \quad$ Köhler 1938, 93-94.}

$35 \quad K o ̈ h l e r$ 1938, 102. Stumpf also believed that the final justification of most categories is to be found within immediate experience. See Stumpf 1939, and Martinelli 2015. 
I wish to remember the new painter's name which I heard yesterday during a conversation. "Just a moment," I say to myself, "I know that I know it; I shall get it at once." Everybody has such experiences. Before a name or another fact is actually remembered there may be a difficulty, a suspense, a delay in its appearance. Nevertheless we may know at the same time that "it is there"; we feel referred, and even referred to the right thing, even though this same thing has not yet emerged into phenomenal existence. ${ }^{37}$

Significantly, here Köhler pays a tribute to William James, who discussed this experience in his Principles of Psychology. ${ }^{38}$ As James put it, in this case there is an "intesively active" gap in our consciousness. "If wrong names are proposed to us, this singularly definite gap acts immediately so as to negate them. They do not fit into its mould"39. According to Köhler's explanation, the painter's name actually lies outside consciousness and, from "there", directs consciousness towards the right solution. When we are presented with wrong names, we are so to speak told "from outside" that the correct solution is still to come. In this case, Köhler believes, one actually experiences transcendence. Within phenomenology, consciousness feels its own incompleteness and claims for completion: the complement, however, clearly resides outside consciousness.

The distinctive trait of transcendence as we observed it, was direct coherence of function, of reference, between an incomplete phenomenal context and a transphenomenal entity. There is only one part of nature which, according to present knowledge, could in this case be so intimately in contact with phenomenal data. This part of nature is the circumscribed world of brain-events. Our conclusion will therefore be that, in trying to remember something and knowing that we know it, our reference is from the point of view of science reference to a definite neurological, or better: neural entity, an entity which would commonly and perhaps clumsily be called a memorytrace. 40

(2) Secondly, Köhler discusses another form of transcendence - namely, the external world beyond our central nervous system. Whereas the formerly discussed argument contrasts with phenomenalism, Köhler now challenges realism. Against both

$\begin{array}{ll}37 & \text { Köhler 1938, } 117 . \\ 38 & \text { Köhler 1938, } 119 . \\ 39 & \text { James 1896, I, } 251 . \\ 40 & \text { Köhler 1938, } 123 .\end{array}$


doctrines, Köhler defends the point of view of "epistemological dualism". Accordingly, phenomenal objects do not coincide with the things of the world; however, phenomenology is not the whole story, because consciousness depends on brain processes. Before discussing this position more extensively, let us consider Köhler's opposition to the so-called New Realism, a school of thought represented among others by R. Barton Parry. New Realists assume that, for any unsophisticated person, there is only one world, which is "the physical world no less than it is the world perceived". However, Köhler is far from advocating an idealistic world view as an alternative to realism. Rather, he thinks that compliance to realism results from a wrong conceptual setting: the new realists rely upon "a most unfortunate pseudoproblem produced by inconsistent thinking". ${ }^{41}$ As previously seen, Köhler distinguishes a subjective side (the 'self') and an objective one (phenomenal objects) within phenomenology. Within this framework, the experience of my own body stands as an object among others. For instance, I see a sheet of paper and a pen on my desk, but also my hands and a part of my two arms.

According to Köhler, the parts of our body belong to the objective part of phenomenal experience, no less than any other inanimate object around us. Now, the above mentioned pseudoproblem originates from a systematic lack of distinction between phenomenal and "transphenomenal" objects. Whenever we say that "percepts depend on processes inside the organism", the organism is a "physical object", whose properties are investigated, for instance, by an anatomist. This object, as such, never recurs within the individual's immediate experience. By contrast, whenever we say that "thing-percepts are located outside myself", the word "myself" refers to something "of which I am aware in the bright daylight of direct phenomenal experience". 42 Accordingly, "when thing-percepts and other phenomena are said to be genetically subjective, to depend upon processes inside the organism, the term 'inside' refers to a physical, a transphenomenal fact"; by contrast, "when thing-percepts are said to be located 'outside myself' the term 'outside' must refer to a strictly phenomenal fact: In

41 Köhler 1938, 127. See also 1929, 224-233 (an analysis that Köhler later considered unsatisfactory) and 1929.

$42 \quad$ Köhler 1938, 129. 
phenomenal space thing-percepts are as a rule localized 'outside' one more percept which I call 'my body'." The inconsistency, Köhler claims, lies in a different meaning of the words: inside means inside my organic body, which never becomes phenomenally evident; by contrast, outside means outside that particular phenomenal object that is my own perceived body. ${ }^{43}$

(3) Finally, Köhler discusses the principle of psycho-physical isomorphism, introduced above. According to this principle, there should be a certain structural homology between the perceived objects and the corresponding physiological brain process. Therefore, Köhler argues, there is a certain homology between the brain process by which, for example, the desk and the book are perceived as outside my hands and my arms, and the corresponding percepts. Similarly, a house, a cloud and a tree are separate things within the phenomenal space. Köhler devotes the entire subsequent chapter to the discussion of isomorphism, partly relying upon his previous researches on the physical Gestalts 44 . Isomorphism, in short, strengthens the thesis that phenomenal experience shows a dichotomy: on the one side, my own body, on the other, all the things surrounding it. Further chapters are devoted to the discussion of the scientific world view, and of mechanism and vitalism in biology 45 . For the present discussion, however, it suffices to point out that Köhler tries to give a scientific basis to his philosophical theory of epistemological dualism.

On the basis of the three above listed arguments, Köhler concludes by endorsing epistemological dualism, which he defines as follows:

Epistemological Dualism holds that percepts cannot be identified with physical objects, because percepts emerge only after many events have happened between the objects and the organism, in peripheral parts of the organism and eventually in the brain. This view seems to lead to a paradox since, as a rule, thing-percepts appear outside our body. We have first shown that this argument is due to an ambiguity of terms. Then, in a discussion of neurological data, we have found that on this ground localization of thing-percepts 'inside ourselves' could never be expected. Much discussion between the New Realists and their opponents would probably have been

\footnotetext{
$43 \quad$ Köhler 1938, 130.

$44 \quad$ “On Isomorphism”: Köhler 1938, 185-232.

45 "On Memory and on Transcendence", "A Discussion of Organic Fitness": Köhler 1938, 233-278; 279-328.
} 
avoided if more attention had been given to these sections of psychology and neurology. 46

In accordance with this evidence, the question as to whether Köhler should be considered a realist or an idealist in philosophy can be reconsidered. In fact, Köhler was neither realist nor idealist. He opposed naive realism, claiming that human perception has no direct grasp of worldly things. Yet he escaped the cage of idealism and firmly believed that a world of things does exist, and that consciousness as a whole depends on one of these things, i.e., the nervous system. One should bear in mind that Köhler did not conceive dualism in an ontological form. He considered the unescapable two-sidedness of phenomenological experience as the first word of philosophy, not its last 47 . Rather, in Köhler's view, epistemological dualism is the only reliable basis for ontological monism, that is, for the claim that there is no substantial difference between the human and the natural world. Both these worlds have their roots in the same physical laws, but these laws involve also instances of requiredness in the earlier mentioned sense. Köhler's analysis of the apparent dichotomy between facts and values testifies of this unifying attitude.

On the basis of epistemological dualism, in fact, Köhler is eventually able to solve the problem of value. Relatedness has no subjective origin - or, at least, not necessarily. Vectors can originate both within the objective and within the subjective side of our phenomenal experience; moreover, they can originate outside experience (in what he calls the "transphenomenal" field) and terminate within it. In sum, requiredness has four main characteristics:

First: A datum, an entity or an act is required within a context of other data, entities or acts. [...]

Secondly: Within the context in question requiredness is a dependent characteristic that has no existence of its own, apart from the entities that fit or do not fit each other in these contexts.

Thirdly: All requiredness transcends from certain parts of a context to others of the same context. Like all other kinds of reference, it is in this sense a directed

\footnotetext{
$46 \quad$ Köhler 1938, 141.

$47 \quad$ As we have seen, in this revival of epistemological dualism Köhler probably relied upon Stumpf. Yet Stumpf claimed that the existence of the external world is a hypothetical construct.
} 
translocal trait, a vector, that cannot be split into bits which have a merely local existence. [...]

Fourthly: Requiredness differs strikingly from other forms of reference by its demanding character. It involves acceptance or rejection of the present status of the context in question, often more particularly, acceptance or rejection of some part by the remainder of the context. This demanding character has degrees of intensity. The lower this intensity, the more will a condition of merely factual relation, juxtaposition or sequence be realized. 48

Köhler points out the formal similarity between these four characteristics and the defining characters of a physical force. Forces are also defined within contexts (fields), they do not exist apart from it, they transcend from a part to another part of the given context, and they also contribute to establish a certain context, or resist to it, with different degrees of intensity. 49 Therefore, there are no grounds for a gap between a physical world of mere facts and a human world of values and necessities (requiredness).

In the final chapter of The Place of Value in a World of Facts, devoted to the relationship between "Man and Nature", Köhler tries to minimize the alleged gap between the world of physics and the world of human values. He agrees that human beings are the result of natural evolution, and that just ordinary natural forces have acted upon their development ${ }^{50}$. However, Köhler notes, a necessary consequence of this is the essential similarity between man and nature. The physicists' suspiciousness of any kind of Aristotelian anthropomorphism is historically legitimate ${ }^{51}$. But there is no justification for an outright dismissal of any attempt of explanation in the field of human values as unscientific. In Köhler's opinion, the price to be payed for this extraordinary extension of the scientific world view is quite modest: a slight revision of some concepts of physics or, more precisely: a perhaps unusual but entirely consistent way of looking at them.

Köhler 1938, 336-337.

Köhler 1938, 342.

50 See also Köhler 1950.

$51 \quad$ Köhler 1938, 373. 


\section{References}

Asch, S.E.

1968 Wolfgang Köhler: 1887-1967. The American Journal of Psychology, 81/1, 110-119.

Ash, G.M.

1995 Gestalt psychology in German Culture, 1890-1967. Holism and the Quest for Objectivity. Cambridge, CUP.

De Monticelli, R.

2013 Requiredness. An Argument for Moral Realism. Phenomenology and Mind. 5, 84-97. Special Issue: The Place of Value in a World of Norms. Ed. by Francesca Forlè and Sarah Songhorian.

Driesch, $\mathrm{H}$.

1925 'Physische Gestalten' und Organismen. Annalen der Philosophie und philosophischen Kritik. 5, 1-11.

Fisette, D. and Martinelli, R. (eds)

2015 Philosophy from an Empirical Standpoint. Essays on Carl Stumpf. Dordrecht: Rodopi.

Henle, M.

1993 Man's Place in Nature in the Thinking of Wolfgang Köhler. Journal of the History of the Behavioral Sciences, 29, 3-7.

1978 One Man against the Nazis. Wolfgang Köhler. American Psychologist, 939-944.

Keiler, P.

1980 Isomorphie-Konzept und Wertheimer-Problem: Beiträge zu einer historischmethodologischen Analyse des Köhlerschen Gestaltansatzes, I. Erkenntnistheoretische und seinslogische Implikationen des Isomorphie-Konzepts. Gestalt Theory 2, 78-112.

Kluck, S.

2008 Gestaltpsychologie und Wiener Kreis, Stationen einer bedeutsamen Beziehung. München: Alber.

Köhler, W.

1971 The Selected Papers of Wolfgang Köhler. Ed. by M. Henle.

1950 Psychology and Evolution. Acta Psychologica, 7, 288-297.

1938 The Place of Value in a World of Facts. London: Kegan Paul, Trench, Trubner \&

Co.

1929 Gestalt Psychology. New York: Liveright.

1926 Zur Komplextheorie. Psychologische Forschung, 8, 236-243. 
1925 The mentality of apes. Translated by the 2nd edition by Ella Winter. London: Kegan Paul, Trench, Trubner \& Co.

1925a Komplextheorie und Gestalttheorie. Antwort auf G.E. Müllers Schrift gleichen Namens. Psychologische Forschung, 6, 358-416.

1920 Die physischen Gestalten in Ruhe und im stationären Zustand. Eine naturphilosphische Untersuchung. Braunschweig: Vieweg; 2nd ed. Erlangen: Verlag der philosophischen Akademie, 1924.

1917 Intelligenzprüfungen an Anthropoiden, Abhandlungen der Königlich Preusssichen Akademie der Wissenschaften. Physikalisch-Mathematische Klasse, Jahrg. 1917, 1-213; repr. Intelligenzprüfungen an Menschenaffen. Mit einem Anhang zur Psychologie des Schimpansen. Berlin: Springer, 1963.

1913 Über unbemerkte Empfindungen

1909 Akustische Untersuchungen,

Martinelli, R.

2015 Stumpf on Categories, in Fisette and Martinelli 2015, 203-227.

Milkov, N.

2013 The Berlin Group and the Vienna Circle: Affinities and Divergences. In Milkov, N. and Peckhaus, V. (eds) The Berlin Group and the Philosophy of Logical Empiricism. Dordrecht: Springer.

2011 Hans Reichenbachs wissenschaftliche Philosophie. In H. Reichenbach, Ziele und Wege der heutigen Naturphilosophie. Hamburg: Meiner, vii-xliv.

Müller, G.E.

1923 Komplextheorie und Gestaltheorie. Ein Beitrag zur Wahrnehmungspsychologie. Göttingen: Vandenhoeck \& Ruprecht.

1926 Bemerkungen zu W. Köhlers Artikel 'Komplextheorie und Gestalttheorie', Zeitschrift für Psychologie, 99, 1-15.

Newman, E.B.

1971 Bibliography of the writings of Wolfgang Köhler. In Köhler 1971, 437-449.

Perry, R.B.

1926 General Theory of Value. Its Meaning and Basic Principles Construed in Terms of Interest. Harvard: Harvard University Press.

Sokal, M.M.

1984 The Gestalt Psychologists in Behaviorist America, The American Historical Review, 89/5, 1240-1263.

Stumpf, C.

1906 Erscheinungen und psychische Funktionen. Abhandlungen der KöniglichPreußischen Akademie der Wissenschaften, Philosophish-historische Classe, Berlin: Verlag der Königlichen Akademie der Wissenschaften, 3-40.

1910 Philosophische Reden und Vorträge. Leipzig: Barth, 1910 
1907 Die Wiedergeburt der Philosophie, Rede zum Eintritt des Rektorates der königlichen Friedrich-Wilhelms-Universität Berlin, 15 Oktober 1907, Berlin: Francke; also in Stumpf 1910, 161-196

1918 Empfindung und Vorstellung. Abhandlungen der Königlich-Preußischen Akademie der Wissenschaften, Philosophisch-historische Klasse 1, 3-116.

1924 Carl Stumpf [Selbstdarstellung]. In R. Schmidt (ed.), Die Philosophie der Gegenwart in Selbstdarstellungen. Leipzig: Meiner, 1-57.

1939-40 Erkenntnislehre, 2 vols., Leipzig: Barth.

Toccafondi, F.

2000 II tutto e le parti. La Gestaltpsychologie tra filosofia e ricerca sperimentale (1912-1922), Milano: F. Angeli. 